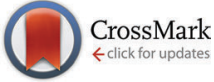

Cite this: New J. Chem., 2016, 40,6604

Received (in Victoria, Australia) 27th January 2016 ,

Accepted 18th May 2016

DOI: $10.1039 / c 6 n j 00287 k$

www.rsc.org/njc

\section{Correlation between structural, physical and chemical properties of three new tetranuclear $\mathrm{Ni}^{\prime \prime}$ clusters $\dagger$}

\author{
Marina Cindrić, ${ }^{\star a}$ Gordana Pavlović, ${ }^{b}$ Damir Pajić, ${ }^{c}$ Krešo Zadro, ${ }^{c}$ Dominik Cinčić, \\ Tomica Hrenar, ${ }^{a}$ Edislav Lekšić, ${ }^{d}$ Ana Belen Pinar Prieto, ${ }^{e}$ Predrag Lazić ${ }^{f}$ and \\ Dubravka Šišak Jung*g
}

\begin{abstract}
Based on a new family of $\mathrm{Ni}^{\prime l}$ cubane-like clusters, this work addresses current challenges in the synthesis, analysis and dynamics of single-molecule-magnet (SMM) systems. Investigation of various synthetic routes and desorption-sorption processes yielded a series of isomorphous compounds: $\left[\mathrm{Ni}_{4} \mathrm{~L}_{4}\left(\mathrm{CH}_{3} \mathrm{OH}\right)_{4}\right] \cdot x$ solv, $\left[\mathrm{Ni}_{4} \mathrm{~L}_{4}\left(\mathrm{CH}_{3} \mathrm{OH}\right)_{4}\right]$ and $\left[\mathrm{Ni}_{4} \mathrm{~L}_{4}\right]$. In order to analyze these deceivingly simple materials, several analytical and quantum mechanical methods had to be used. This revealed materials with mixed lattice solvents, statistical disorder of the solvent, and disordered $\left[\mathrm{Ni}_{4} \mathrm{~L}_{4}\right]$ cores which offered an insight into the risks of the self-assembly process and interconversion dynamics of the investigated $\mathrm{Ni}^{\text {il family. }}$ These findings also allowed structural-magnetic relationships to be established, and the outcomes were exploited in two ways: first, the effect of the coordinated and lattice solvent on the magnetic properties was examined, and second, magnetic properties were used to facilitate crystal structure determination.
\end{abstract}

\section{Introduction}

Single-molecule magnets (SMM) are a specific class of metalloorganic complexes whose magnetic behavior depends on the intrinsic magnetic properties of the individual molecules, i.e. it is a direct consequence of inter- and intramolecular interactions in the system. In general, the choice of ligands will govern the topology of the system, as well as the number and type of intra- and intermolecular interactions. ${ }^{1-3}$ This, in turn, depends on the choice of the synthetic route, and synthetic parameters such as temperature, $\mathrm{pH}$ and metal-to-ligand ratio

\footnotetext{
${ }^{a}$ University of Zagreb, Faculty of Science, Department of Chemistry, Horvatovac 102a, HR-10000 Zagreb, Croatia. E-mail: marina@chem.pmf.hr; Fax: +38514606341

${ }^{b}$ University of Zagreb, Faculty of Textile Technology, Department of Applied Chemistry, Prilaz baruna Filipovića 28a, HR-10000 Zagreb, Croatia

${ }^{c}$ University of Zagreb, Faculty of Science, Department of Physics, Bijenička cesta 32, HR-10000 Zagreb, Croatia

${ }^{d}$ PLIVA Croatia, TAPI R\&D, Prilaz Baruna Filipovića 25, HR-10000 Zagreb, Croatia

${ }^{e}$ ETH Zurich, Laboratory for Crystallography, Vladimir-Prelog-Weg 5, 8093 Zurich, Switzerland

${ }^{f}$ Institute Ruđer Bosković, Department for Theoretical Physics, Bijenička cesta 54, 10000 Zagreb, Croatia

${ }^{g}$ DECTRIS Ltd, Täfernweg 1, 5405 Baden-Dättwil, Switzerland.

E-mail: dubravka.sisak@dectris.com

$\dagger$ Electronic supplementary information (ESI) available. CCDC 1015860-1015863. For ESI and crystallographic data in CIF or other electronic format see DOI: 10.1039/c6nj00287k
}

play an important role in the synthesis of the targeted product. As these systems found their potential application in data storage, memory devices, switches and sensors, the targeted synthesis of SMMs became increasingly important. ${ }^{4}$ Significant progress in synthesis was made by implementation of various "bottom-up" approaches based on the sensible choice of ligands and metal ions. These facilitated the formation of clusters with well-defined geometries and related magnetic properties. $^{5-7}$ In the last two decades, a series of compounds based on polynuclear complexes of $\mathrm{Mn}, \mathrm{Fe}, \mathrm{Ni}, \mathrm{V}$ and $\mathrm{Co}$, or mixed metals have been reported, ${ }^{8-10}$ of which cubane-like magnetic clusters with a $\left[\mathrm{Ni}_{4}\left(\mu_{3}-\mathrm{O}\right)_{4}\right]$ core are especially a wellstudied class. ${ }^{11-21}$ Particular interest in this class of compounds arises from their specific core shape and magnetic exchange pathways, governed by $\mu_{3}$-atoms. Consequently, extensive investigations of the $\left[\mathrm{Ni}_{4}\left(\mu_{3}-\mathrm{O}\right)_{4}\right]$ core provided an insight into the delicate relationship between magnetic and structural properties. ${ }^{22-24}$ The importance of the exact geometry of the $\left[\mathrm{Ni}_{4} \mathrm{O}_{4}\right]$ core is emphasized in a series of studies, as the symmetry and the corresponding $\mathrm{Ni}-\mu_{3}-\mathrm{O}-\mathrm{Ni}$ angles play a crucial role in the intramolecular magnetic interactions. ${ }^{25-27}$ Moreover, fine details of the cluster structure, such as the type and the amount of solvent, are extremely important, as these factors can determine the magnetic properties of SMM systems. This solvent-effect was first reported in 1999 by Khan and Larinova, who introduced the concept of a "magnetic sponge" to describe magnetic materials that can reversibly release and reabsorb both coordinated and 
non-coordinated solvent molecules. ${ }^{28}$ Nowadays, solvent effects are becoming increasingly interesting. In the latest investigation of $\left[\mathrm{Ni}_{4} \mathrm{~L}_{4}(\mathrm{solv})_{4}\right]$ type of complexes it was shown that at ambient temperature, these compounds show reversible exchange of the coordinated solvent molecules $\left(\mathrm{MeOH}\right.$ vs. $\left.\mathrm{H}_{2} \mathrm{O}\right)$, causing the spin to switch the ground state from $S=4$ to $S=0 .{ }^{29}$ Even more interesting is the recent research of desolvation of SMM materials $\left(\mathrm{Mn}_{12},{ }^{30} \mathrm{Fe}_{4}^{\mathrm{III}}{ }^{31}\right.$ metal-organic frameworks $\left.{ }^{32}\right)$ reporting a serious effect of lattice (non-coordinated) solvents and experimental conditions on magnetic properties. All these findings inspired us to study the dynamics of exchange of coordinated and noncoordinated solvents in a new family of $\mathrm{Ni}^{\mathrm{II}}$ cubane-like clusters, comprising $\left[\mathrm{Ni}_{4} \mathrm{~L}_{4}\left(\mathrm{CH}_{3} \mathrm{OH}\right)_{4}\right] \cdot x$ solv, $\left[\mathrm{Ni}_{4} \mathrm{~L}_{4}\left(\mathrm{CH}_{3} \mathrm{OH}\right)_{4}\right]$ and $\left[\mathrm{Ni}_{4} \mathrm{~L}_{4}\right]$ compounds. Investigation of synthetic paths, desorption-sorption studies, stability and interconversion processes of these closely related compounds offered a more detailed insight into the outcome of the self-assembly processes. Structural analyses of the obtained compounds, coupled with quantum mechanical studies, were correlated with magnetic measurements. The findings were exploited in two ways. First, the effect of the type and the amount of the solvent in the structure on the magnetic properties was examined, and second, magnetic properties were used to facilitate crystal structure determination.

\section{Results and discussion}

\section{Synthesis}

Depending on the synthetic strategy, deep green plates $\left[\mathrm{Ni}_{4} \mathrm{~L}_{4}\right.$ $\left.\left(\mathrm{CH}_{3} \mathrm{OH}\right)_{4}\right] \cdot 0.32 \mathrm{CH}_{3} \mathrm{OH} \cdot 0.32 \mathrm{H}_{2} \mathrm{O}(\mathbf{1})$ or green hexagonal prisms $\left[\mathrm{Ni}_{4} \mathrm{~L}_{4}\left(\mathrm{CH}_{3} \mathrm{OH}\right)_{4}\right] \cdot 0.63 \mathrm{CH}_{3} \mathrm{OH}(2)$ were obtained from the reaction mixture (Scheme 1).

Compound 1 was prepared by solvothermal reaction of $\mathrm{Ni}\left(\mathrm{O}_{2} \mathrm{CMe}\right)_{2} \cdot 4 \mathrm{H}_{2} \mathrm{O}$ and the tridentate Schiff base $N$-(2-hydroxy5-methylphenyl)salicylideneimine $\left(\mathrm{H}_{2} \mathrm{~L}\right)$ in methanol at $110{ }^{\circ} \mathrm{C}$. However, only slight modifications of the original solvothermal reaction in methanol at $110{ }^{\circ} \mathrm{C}$ resulted in different products. The change in temperature from $110{ }^{\circ} \mathrm{C}$ to room temperature yielded green hexagonal prisms of compound 2. Furthermore, adding water to the mixture $\left(2.5 \mathrm{MeOH}: 1 \mathrm{H}_{2} \mathrm{O}\right.$, volume ratio) resulted in green plates $\mathbf{1}$, while adding acetic anhydride to the reaction mixture yielded compound 2 . In both cases, it was noticed that the synthesis path is not sensitive to the molar ratio of the precursors. Under the same synthetic conditions, both $1: 1$ and $1: 2$ precursor ratios yielded the same products.

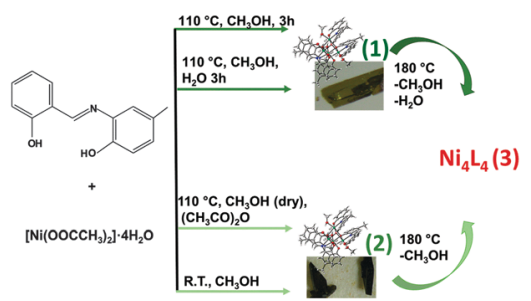

Scheme 1 Synthesis of two green clusters $\left[\mathrm{Ni}_{4} \mathrm{~L}_{4}\left(\mathrm{CH}_{3} \mathrm{OH}\right)_{4}\right] \cdot 0.32 \mathrm{CH}_{3} \mathrm{OH}$. $0.32 \mathrm{H}_{2} \mathrm{O}(\mathbf{1})$ and $\left[\mathrm{Ni}_{4} \mathrm{~L}_{4}\left(\mathrm{CH}_{3} \mathrm{OH}\right)_{4}\right] \cdot 0.63 \mathrm{CH}_{3} \mathrm{OH}(\mathbf{2})$ and one red cluster of the formula $\left[\mathrm{Ni}_{4} \mathrm{~L}_{4}\right](3)$.

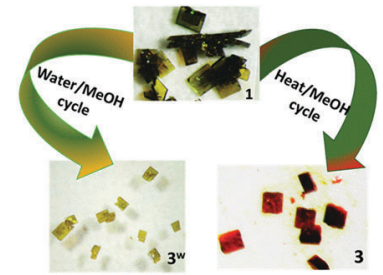

Scheme 2 Transformation of cluster 1 in the heat/MeOH and water/ $\mathrm{MeOH}$ cycle.

Although these experiments showed that $\mathbf{1}$ and $\mathbf{2}$ products are kinetically and thermodynamically favored, it also became apparent that water molecules compete with methanol for a place in the crystal lattice, and that the outcome can depend on the temperature and solvent mixture. This flexibility of the systems was further supported by stability and sorption studies. When exposed to room conditions, both materials $\mathbf{1}$ and 2 changed the colour from green to orange-red. While these conversions resulted in similar products $\mathbf{1 a}$ and $\mathbf{2 a}$, their respective kinetics differed. The products $1 \mathbf{a}$ and $2 \mathbf{a}$ have the same molecular formula, $\left[\mathrm{Ni}_{4} \mathrm{~L}_{4}\left(\mathrm{CH}_{3} \mathrm{OH}\right)_{4}\right]$, but their structures are slightly different. Conversion $\mathbf{1} \rightarrow \mathbf{1 a}$ took one day, and $\mathbf{2} \rightarrow$ 2a only a few hours, indicating different types of intermolecular interactions (in $\mathbf{1}$ and 2 ) between the $\mathrm{Ni}^{\mathrm{II}}$ complex and the noncoordinated solvent. Considering that the reactions resulted in single crystal species, a subtle structural change upon the loss of the non-coordinated solvent could be proposed. In contrast to the room temperature observations described above, heating of clusters 1 and 2 up to $180{ }^{\circ} \mathrm{C}$ resulted in the red polycrystalline sample 3 (Scheme 2).

When exposed to methanol, the colour of the material changed back to green, indicating that sample $\mathbf{3}$ is most likely to have the formula $\mathrm{Ni}_{4} \mathrm{~L}_{4}$. Additionally, sorption experiments conducted on compounds 1 and 2 with water vapors showed that water molecules can be incorporated as solvents in the crystal lattice (Fig. S1-S18, ESI $\dagger$ ). These processes (sorption/ desorption, ageing, and heating) yielded a variety of materials, with different types and amounts of coordinated and crystalline solvents, which required a multitude of analytical techniques to be used: single crystal X-ray diffraction (SCXRD), X-ray powder diffraction (XRPD), thermogravimetry (TG), infrared spectroscopy, chromatography and magnetic measurements. A combination of these techniques with quantum mechanical calculations allowed for characterization of the obtained materials, and thus structure-magnetic relationships to be proposed.

\section{Thermogravimetric analysis (TG)}

In order to examine the solvent content and thermal stability of clusters 1, 2 and 3 the samples were heated in an oxygen atmosphere from 25 to $600{ }^{\circ} \mathrm{C}$. Clusters 1 and 2 displayed one-step weight loss, occurring between 25 and $180{ }^{\circ} \mathrm{C}$, and 40 and $140{ }^{\circ} \mathrm{C}$, respectively. Such behaviour was ascribed to the combined loss of lattice and coordinated solvent molecules. However, in the case of compound 1, the relative amounts of water and methanol could not be discerned. The further weight 
loss occurring between 340 and $430{ }^{\circ} \mathrm{C}$ (for 1), and 300 and $430{ }^{\circ} \mathrm{C}$ (for 2) was associated with cluster degradation (Fig. S19 and S20, ESI $\dagger$ ). Compound 3 was found to undergo a one-step weight loss in the temperature range $302-540{ }^{\circ} \mathrm{C}$, which confirmed the absence of both lattice and coordinated solvent molecules. Thermal stability of the samples obtained by sorption/ desorption or by ageing of materials $\mathbf{1}$ and $\mathbf{2}$ showed that the combined loss of lattice and coordinated solvent molecules occurred in one step up to $160{ }^{\circ} \mathrm{C}$ and $130{ }^{\circ} \mathrm{C}$. This is very similar to that described for compounds $\mathbf{1}$ and 2, and the small differences could be a consequence of different contents of solvent molecules.

\section{Structural studies}

Single-crystal X-ray structure analysis revealed that compounds 1, 1a, 2 and $\mathbf{2 a}$ are tetranuclear $\left[\mathrm{Ni}_{4}\left(\mu_{3}-\mathrm{O}\right)_{4}\right]$ clusters with a distorted cubane topology. $\mathrm{Ni}^{\mathrm{II}}$ and the $\mu_{3}-\mathrm{O}$ oxygen atoms of the methylphenolato moiety from Schiff base ligands $\left(\mathrm{L}^{2-}=\right.$ $\left.\mathrm{C}_{6} \mathrm{H}_{5}(\mathrm{O})-\mathrm{C}=\mathrm{N}-(\mathrm{O}) \mathrm{C}_{6} \mathrm{H}_{4} \mathrm{CH}_{3}\right)$ occupy alternate vertices of the cube, resulting in interpenetrating two concentric tetrahedra, one made by the nickel centres and another by the asymmetrically spanning $\mu_{3}-\mathrm{O}$ oxygen atoms. Each $\mathrm{Ni}^{\mathrm{II}}$ ion is six-coordinated by five oxygen atoms and one imino nitrogen atom. Three of five oxygen atoms are oxygen atoms of the methylphenolato moiety which span three nickel centres, one is from the neutral $\mathrm{MeOH}$ monodentate ligand and the fifth is the oxygen atom from the salicylideneimine part of the ligand (Fig. 1). In the case of compound 1, methanol and water were present as lattice solvents, while in compound 2 , only methanol solvent was found, resulting in general formulae $\left[\mathrm{Ni}_{4} \mathrm{~L}_{4}\left(\mathrm{CH}_{3} \mathrm{OH}\right)_{4}\right] \cdot 0.32 \mathrm{CH}_{3} \mathrm{OH} \cdot 0.32 \mathrm{H}_{2} \mathrm{O}(\mathbf{1})$ and $\left[\mathrm{Ni}_{4} \mathrm{~L}_{4}\left(\mathrm{CH}_{3} \mathrm{OH}\right)_{4}\right]$. $0.63 \mathrm{CH}_{3} \mathrm{OH}(2)$. The solvent molecules, $\mathrm{MeOH} / \mathrm{H}_{2} \mathrm{O}$ and $\mathrm{MeOH}$, in the unit cell of compounds were highly disordered and their respective amounts could not be derived from SCXRD data only. These values were obtained by combining chromatographic and SCXRD data. Coulometric titration and head-space gas chromatography were used for the determination of water and methanol in 1 and 2, respectively. The unit cell volumes of $\mathbf{1}$ and $\mathbf{2}$ differ by $32 \AA^{3}$ which is $1 \%$ of the unit cell volume. As expected, the crystal structures of compounds $\mathbf{1 a}$ and $2 \mathbf{2}$ showed a similar $\mathrm{Ni}^{\mathrm{II}}$ core, with no solvent incorporated into the lattice (Fig. S21, $\mathrm{ESI} \dagger)$. The difference in the unit cell volumes of $\mathbf{1 a}$ and $2 \mathbf{a}$ is not negligible (less than $1 \%$ of unit cell volume), and it is an indication of possible small structural differences between $\mathbf{1 a}$ and $\mathbf{2 a}$.

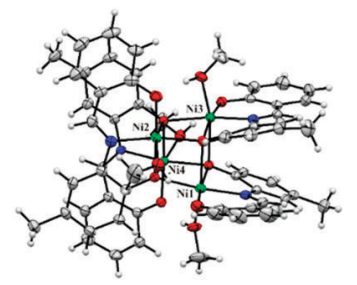

Fig. 1 Mercury-rendered ORTEP view of the molecular structure of cluster 1 (color scheme applied: green - nickel, red - oxygen, blue - nitrogen, grey - carbon, light grey - hydrogen). The displacement ellipsoids are drawn at the $50 \%$ probability level at $150 \mathrm{~K}$. The $\mathrm{CH}_{3} \mathrm{OH}$ and $\mathrm{H}_{2} \mathrm{O}$ molecules present as lattice solvents are omitted for clarity.

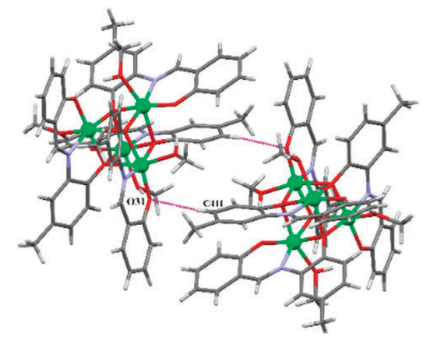

Fig. 2 Pov-Ray ${ }^{34}$ (v.3.62) rendered drawing of formation of the centrosymmetric dimers (shown for 1a) via the weak C411-H411...031 intermolecular hydrogen bond between the phenyl $\mathrm{C} 411-\mathrm{H} 411$ group of the 4-methylphenolato moiety and the phenolate oxygen atom $\mathrm{O} 31$ (broken magenta lines). The metrical parameters are given in Table S3 (ESI $\uparrow$ ).

All four crystal structures (1, 1a, 2, and 2a) exhibit intramolecular hydrogen bonds between hydroxyl groups of coordinated $\mathrm{MeOH}$ molecules and phenolate oxygen atoms. However, no intermolecular classical hydrogen bonds were observed. In all investigated structures $(\mathbf{1}, \mathbf{1 a}, \mathbf{2}$, and $\mathbf{2 a})$, the tetrameric unit is cross-linked by $\mathrm{C}-\mathrm{H} \cdots \mathrm{O} / \mathrm{N}$ intramolecular hydrogen bonds of expected geometries. The basic supramolecular motif that is common for all structures at either room or low temperature is the dimerization of cluster units via the $\mathrm{C}-\mathrm{H} \cdots \mathrm{O}$ type of the weak hydrogen bond (Fig. 2). C $\cdots \mathrm{O}$ and $\mathrm{H} \cdots \mathrm{O}$ separations are approximately 3.4 and $2.5 \AA$, respectively, in the low-temperature structures 1 and 2 and 3.5 and $2.6 \AA$ in the room-temperature structures 1a and 2a. The $\mathrm{H} \cdots \mathrm{O}$ separations fall in the long distance range for $\mathrm{H} \cdot \mathrm{A}$ A contacts, according to T. Steiner. ${ }^{33}$ The pertinent structural parameters are listed in Tables S1-S6 in the ESI $\dagger$ in addition to a detailed description of the molecular and crystal structures (Scheme S1 and Fig. S22-S24, ESI $\dagger$ ).

Compounds 1 and 1a, and on the other side, 2 and 2a, differ in $\mathrm{C}-\mathrm{H} \cdots \mathrm{O}$ intermolecular hydrogen bonds formed with noncoordinated $\mathrm{MeOH} / \mathrm{H}_{2} \mathrm{O}$ molecules and $-\mathrm{C}_{6} \mathrm{H}_{5}$ phenyl groups of the ligand. Their geometries belong to the long distance range of approx. 3.6 $\AA$ (for C . .O) indicating that the solvent molecules are weakly bound to the tetranuclear cluster unit. A detailed inspection of the metrical parameters of these hydrogen bonds reveals that $\mathrm{H} \cdots \mathrm{O}$ distances in $\mathbf{1}$ are generally shorter $(2.30-2.75 \AA)$ than in 2 (2.86 $\AA$ ) (Table S3, see hydrogen bonds with the O1W and $\mathrm{O} 5$ atoms acting as proton-acceptors in 1 vs. one hydrogen bond with the O5A atom as a proton-acceptor in 2, ESI $\dagger$ ).

Structural analysis of cluster 3 , a red polycrystalline material obtained by thermal treatment of cluster 1 (or 2), was carried out using XRPD data, as described in detail in the Experimental section. At this point, it is important to differentiate between the ideal structure that corresponds to the energetically ideal case, as found by DFT-optimizations, and the average structure of the investigated material, which was found to be disordered (XRPD pattern) (Fig. 3).

As expected, the ideal structure of compound 3 featured two $\mathrm{Ni}_{4} \mathrm{~L}_{4}$ species with distorted cubane-type geometry, where each $\mathrm{Ni}$ atom exhibits square planar coordination: three oxygens from methylphenolato moieties and one imino nitrogen atom. All corresponding $\mathrm{Ni}-\mathrm{O}-\mathrm{Ni}$ bond angles are found to be larger 


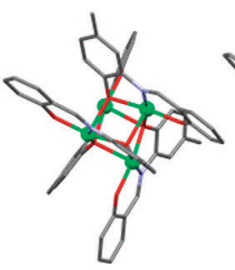

a)

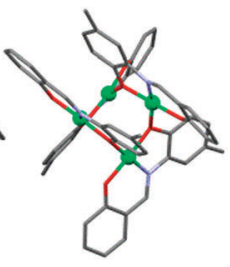

b)

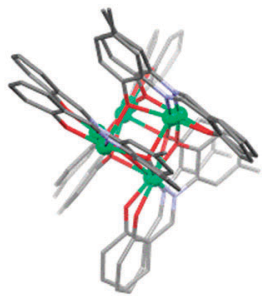

c)
Fig. 3 Molecular structures of compound 3. Starting models: (a) obtained by removing methanol molecules from structure 1 and (b) after DFT-optimization. Final models: (c) molecular structure obtained from XRPD data (average structure) superimposed on the DFT-optimized structure (ideal structure).

than $90^{\circ}$ (Table S7, ESI $\dagger$ ). Considering that Bertrand and co-workers already suggested in 1971 that the deviation of $\pm 14^{\circ}$ from $90^{\circ}$ angles can be tolerated before the direct ferromagnetic exchange terms cease to be dominant, this structure suggested diamagnetic behaviour of the molecule. ${ }^{35}$ Each $\mathrm{Ni}_{4} \mathrm{~L}_{4}$ cluster exhibits two intramolecular $\mathrm{C}-\mathrm{H} \cdots \mathrm{O}$ bonds, formed between the oxygen and carbon from methylphenolato moieties. One $\mathrm{C}-\mathrm{H} \cdots \mathrm{O}$ bond is formed between two parallelly aligned ligands and the other connects two neighbouring perpendicular ligands. The structure of cluster 3 features a series of intra- and intermolecular $\mathrm{C}-\mathrm{H} \cdots \pi$ hydrogen bonds, established between the methyl group and the aromatic chelate six-membered ring of the coordinated ligand. In particular, the intramolecular $\mathrm{C}-\mathrm{H} \cdots \pi$ bond is formed between one set of parallelly aligned ligands. Intermolecular bonds of the same type showed a much richer network: $\mathrm{C}-\mathrm{H} \cdots \pi$ interactions were established between parallelly and perpendicularly oriented neighbouring ligands, forming a rich network across the crystal. This description of the ideal structure of cluster 3 allowed diamagnetic behaviour to be proposed. However, examination of the peak widths in the XRPD pattern (Fig. 4) suggested that the material exhibits both crystalline and disordered domains, while a high background suggested that species with low-range order could also be present in the material. Therefore, the average structure of the material and its influence on magnetic properties required further analysis.

Considering the facts that (i) cluster 3 was obtained by thermal treatment of cluster $\mathbf{2 a}(\mathbf{1 a})$, (ii) the molecular structure

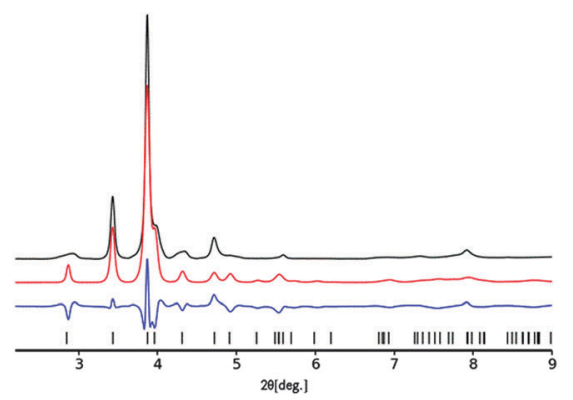

Fig. 4 Observed (black), calculated (red) and difference (blue) profiles for the Rietveld refinement of compound 3 . Reflection positions are marked as vertical bars. is stabilized by $\mathrm{C}-\mathrm{H} \cdots \mathrm{O}$ and $\mathrm{C}-\mathrm{H} \cdots \pi$ interactions and (iii) the crystal structure of cluster 3 is governed mostly by weak $\mathrm{C}-\mathrm{H} \cdots \pi$ interactions, the following explanation can be proposed. In order to remove coordinated methanol from material 2a (1a), the molecule needs to adopt a suitable geometry. Four ligands in the $\mathrm{Ni}_{4} \mathrm{~L}_{4}$ cluster need to be slightly shifted and rotated, which results in increased $\mathrm{Ni}-\mathrm{O}-\mathrm{Ni}$ angles. While this increase generates square-planar geometry of the $\mathrm{Ni}_{4} \mathrm{~L}_{4}$ cluster, the resulting $\mathrm{Ni}-\mathrm{O}-\mathrm{Ni}$ angles do not need to be increased isotropically. Due to the rich inter- and intramolecular interactions of $\mathrm{C}-\mathrm{H} \cdots \mathrm{O}$ and $\mathrm{C}-\mathrm{H} \cdots \pi$ type, $\mathrm{Ni}-\mathrm{O}-\mathrm{Ni}$ angles can adopt a wide range of values. Consequently, such a range of molecular geometries can exhibit slightly different magnetic properties. Moreover, ambiguities in unit cell determination and the possible presence of species with a local structure also need to be taken into account. First, a limited number of peaks and anisotropic peak broadening allowed only average (most probable) values of unit cell parameters to be determined: existence of other, slightly different cells or supercells cannot be excluded. Second, the possible local structure will also contribute to the magnetic behaviour. Thus, deviations from ideal magnetic values can be expected. However, although the material features disordered domains, it appears to be thermodynamically stable. Comparison of the initial XRPD pattern with the pattern collected after two months, using the same setup, revealed no differences.

\section{Sorption and stability studies}

In a series of sorption and ageing studies, the stability of synthesised compounds, desolvation-solvation processes, and possibilities of interconversions of non-coordinated solvents were investigated.

Water sorption studies on 1 and 2 clusters. Water sorption/ desorption isotherms were measured using an accurate humidityand temperature-controlled microbalance system, at $26{ }^{\circ} \mathrm{C}$. The $\mathrm{RH}$ was increased in steps from 0 to $90 \%$, where each step corresponds to an increase of relative humidity of $10 \%$ (1 cycle). Similarly, desorption ( $90 \%$ to $0 \% \mathrm{RH}$ ) was carried out cycle-wise, where each cycle corresponds to a decrease of relative humidity of 10\% (Tables S8 and S9; Fig. S25 and S26, ESI $\dagger$ ).

At $90 \% \mathrm{RH}$, both complexes 1 and 2 showed that water sorption resulted in an increase of mass of less than $0.1 \%$. The corresponding desorption curve did not match the absorption curve, and showed a decrease in mass of about $2.5 \%$ and $4 \%$ for compounds 1 and 2, respectively. Considering that both structures 1 and 2 feature dynamical disorder $\left(0.32 \mathrm{H}_{2} \mathrm{O}\right.$ and $0.32 \mathrm{CH}_{3} \mathrm{OH}$ for structure 1, and $0.63 \mathrm{CH}_{3} \mathrm{OH}$ in compound 2) these values indicate that during sorption, water molecules are incorporated into the structure until voids in the crystal are fully occupied by water, that is, until every unit cell is occupied by solvent molecules. The morphology of both the clusters was held but strong surface erosion was observed in cluster 2 (Fig. S27, ESI $\dagger$ ).

Interconversions under non-ambient conditions. Ageing of compounds 1 and 2 was tested by exposing them to solvent vapors in three cycles. In the first cycle, compound 1 (2) was exposed to $75 \% \mathrm{RH}$ for seven days. In the second, the obtained material was exposed to $\mathrm{MeOH}$ vapors, and in the third, again to water. 
In both cases ( $\mathbf{1}$ and 2 ), comparison of the XRPD patterns obtained at each cycle showed differences in peak positions and their relative intensities (Fig. 5a). These differences showed that $\mathrm{H}_{2} \mathrm{O} / \mathrm{MeOH}$ recycling does not lead to a unique product and indicated that both lattice and coordinated solvents can be exchanged (for details, see Fig. S1-S18, ESI $\dagger$ ). In recycling by annealing, compound 1 (2) was annealed at $180{ }^{\circ} \mathrm{C}$ and then exposed to $\mathrm{MeOH}$ vapors in three cycles. Comparison of XRPD patterns collected for samples exposed to $\mathrm{MeOH}$ vapors revealed differences in relative peak intensities (green in Fig. 5b), showing once again that the process is not fully reversible. If these differences are correlated with TG-studies, they can be explained as variations in the amount of lattice solvent present in the material. Similar differences observed between XRPD patterns obtained by annealing (red in Fig. $5 \mathrm{~b}$ ) suggest that the $\mathrm{Ni}_{4} \mathrm{~L}_{4}$ core can adopt a slightly different structure.
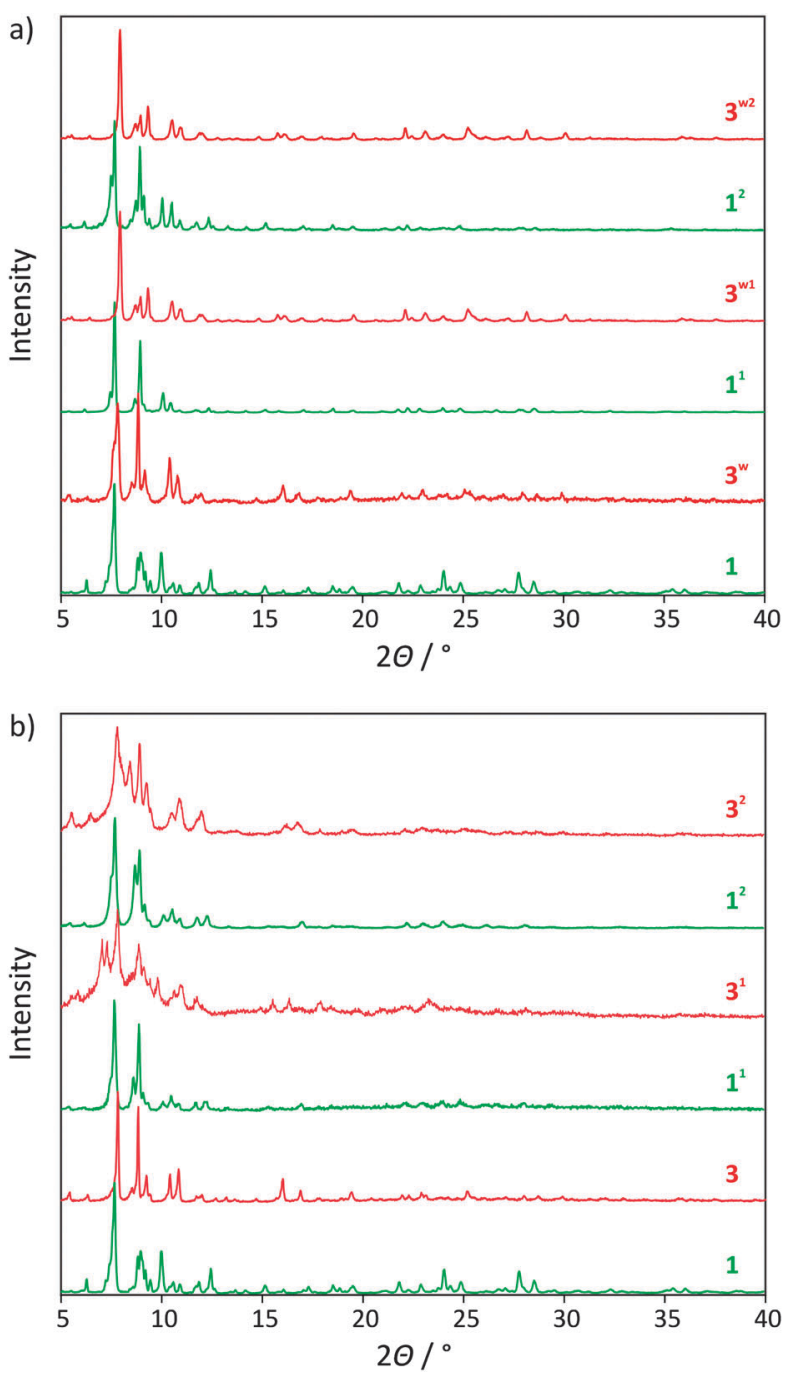

Fig. 5 (a) PXRD patterns for 1 obtained after ageing of 1 in water (water$\mathrm{MeOH}$ cycle) vapor in the 1st $\left(\mathbf{1} \rightarrow \mathbf{3}^{\mathrm{w}}\right)$, 2nd $\left(\mathbf{1}^{\mathbf{1}} \rightarrow 3^{\mathrm{w} \mathbf{1}}\right)$ and $3 \mathrm{rd}\left(\mathbf{1}^{\mathbf{2}} \rightarrow \mathbf{3}^{\mathrm{w} \mathbf{2}}\right)$ cycle; (b) PXRD pattern for 1 obtained after annealing of 1 at $180{ }^{\circ} \mathrm{C}$ and after 7 days of ageing in $\mathrm{MeOH}$ vapor (heat-MeOH cycle) in the 1st $(\mathbf{1} \rightarrow \mathbf{3}$ ), 2nd $\left(1^{1} \rightarrow 3^{1}\right)$ and 3 rd $\left(1^{2} \rightarrow 3^{2}\right)$ cycle.

\section{Magnetic studies}

In order to establish magneto-structural correlations, two series of magnetic investigations were carried out for compounds 1, 2 and 3 (Fig. S28-S33, ESI $\dagger$ ). The first series (heat-MeOH cycle) temperature dependence of the molar magnetic susceptibility of (a) clusters $3 \rightarrow \mathbf{3}^{3}$ obtained after annealing of $\mathbf{1} \rightarrow \mathbf{1}^{\mathbf{3}}$ and (b) clusters $\mathbf{1}^{\mathbf{1}} \rightarrow \mathbf{1}^{\mathbf{3}}$ obtained by exposing clusters $\mathbf{3} \rightarrow \mathbf{3}^{\mathbf{3}}$ to $\mathrm{MeOH}$ vapors is shown in Fig. 6 (for 2 Fig. S32, ESI $\dagger$ ).

The second series (water-MeOH cycle) changes of magnetic behavior are induced by exposure of $\mathbf{1}$ (or 2) to water and methanol vapors alternatively (Fig. 7). The return to the initial state is almost equally effective in both cycles after exposure to methanol vapors. Small differences in the efficacy are connected with small differences in the dynamics of solvent release observed in other experiments.

The Curie constant $C$ of the first series clusters $\mathbf{1} \rightarrow \mathbf{3} \rightarrow$ $\mathbf{1}^{1} \rightarrow 3^{1} \rightarrow 1^{2} \rightarrow 3^{2} \rightarrow 1^{3} \rightarrow 3^{3}$, in the heat-MeOH cycle, has a mean value of 5.1(3) $\mathrm{K} \mathrm{emu} \mathrm{mol}^{-1} \mathrm{Oe}^{-1}$. This value confirms that in the starting green cluster $\mathbf{1}$ and recycled compounds (also green clusters $\mathbf{1}^{\mathbf{1}}, \mathbf{1}^{\mathbf{2}}$ and $\mathbf{1}^{\mathbf{3}}$ ) the four spin 1 nickel ions per formulae unit are magnetically uncoupled at the high temperatures. The obtained $g$-factors $(2.26,2.21,2.19$ and 2.19) are in agreement with the expected values for $\mathrm{Ni}$ ions in octahedral coordination, within the $2 \%$ error of the measurement. ${ }^{12,15,25}$ Below $\sim 100 \mathrm{~K}$, the susceptibility starts to deviate from the Curie-Weiss law, and the $\chi T$ product increases, reaching max. at $3.8 \mathrm{~K}$, suggesting the ferromagnetic coupling within the cubane. The red cluster $\mathbf{3}$ (and also red clusters $\mathbf{3}^{\mathbf{1}}, \mathbf{3}^{\mathbf{2}}$, and $\mathbf{3}^{\mathbf{3}}$ ) of the formula $\left[\mathrm{Ni}_{4} \mathrm{~L}_{4}\right]$ has completely different magnetic properties; its effective magnetic moment per formula unit is considerably smaller than in $\left[\mathrm{Ni}_{4} \mathrm{~L}_{4}\left(\mathrm{CH}_{3} \mathrm{OH}\right)_{4}\right] \cdot 0.32 \mathrm{CH}_{3} \mathrm{OH} \cdot 0.32 \mathrm{H}_{2} \mathrm{O}, 1$. Modelling the

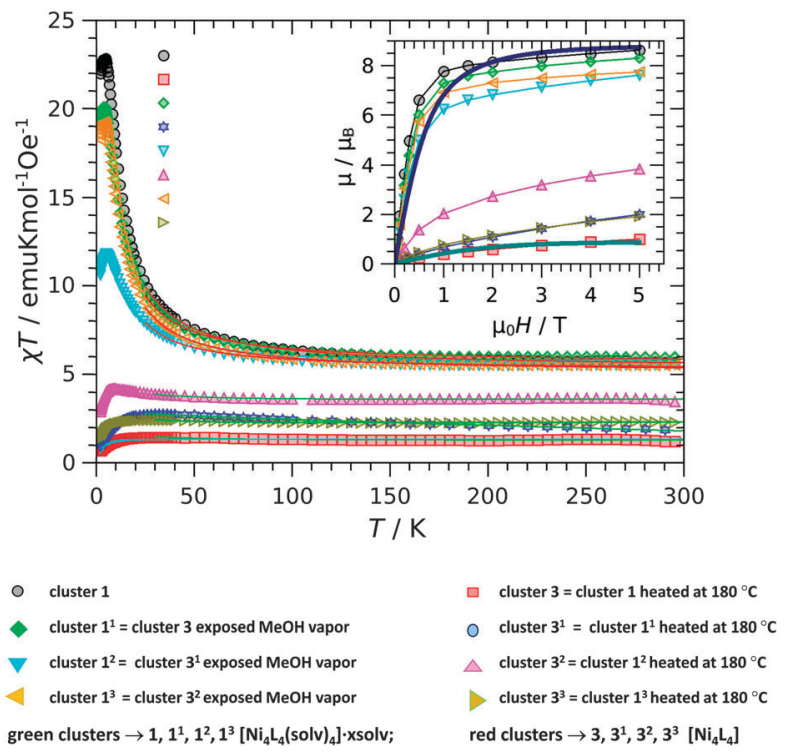

Fig. 6 Temperature dependence of molar magnetic susceptibility measured in the field of $0.1 \mathrm{~T}$ multiplied with temperature, for cluster 1 series (heated compound $3,\left[\mathrm{Ni}_{4} \mathrm{~L}_{4}\right]$ obtained by annealing of 1 and recycled by exposing to methanol vapors in turn). Lines are fitting curves. Inset: field dependence of magnetization per cubane unit measured at the temperature of $2 \mathrm{~K}$. 

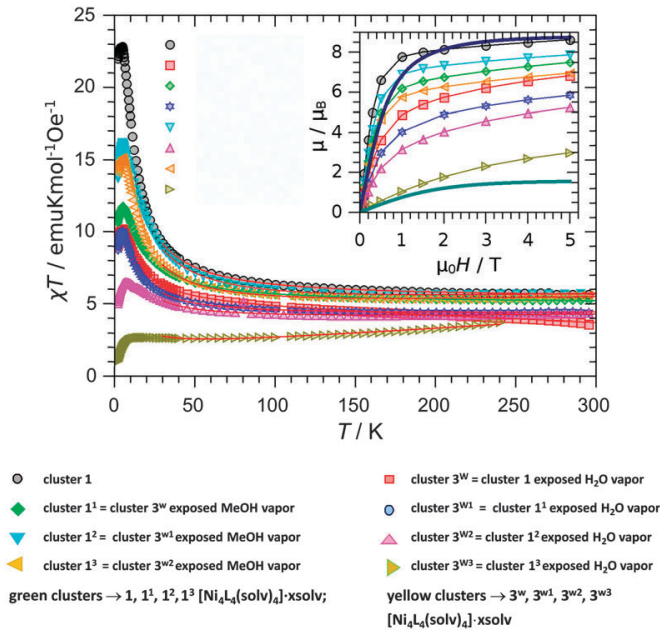

Fig. 7 Temperature dependence of molar magnetic susceptibility measured in the field of $0.1 \mathrm{~T}$ multiplied with temperature, for cluster 1 series, measured successively after exposure to water vapor and recycling in methanol vapor alternately. Lines are fitting curves. Inset: Field dependence of magnetization per cubane unit measured at the temperature of $2 \mathrm{~K}$.

temperature behaviour of the susceptibility with the CurieWeiss law gives the $C$ values in the range from 1.4 to $3.4 \mathrm{~K}$ emu $\mathrm{mol}^{-1} \mathrm{Oe}^{-1}$. This decrease indicates the partial transition, between 24 and 64\% (sample dependent), of $\mathrm{Ni}^{\mathrm{II}}$ ions from spin 1 to the diamagnetic state. The explanation of this effective magnetic moment reduction is possible only with the transition of some $\mathrm{Ni}^{\mathrm{II}}$ ions from spin 1 to spin 0 state. Namely, the obtained $C$ constant is too small to originate from the four spins 1 per cubane unit, and because of the structural improbability of the large antiferromagnetic coupling surviving in the whole temperature range, reduction of the number of magnetic units is the obvious prerequisite. It is known that spin 1 to spin 0 transition for nickel ions occurs with the change of coordination when the electron levels of $t_{2 g}$ and $e_{g}$ orbitals change their order when compared to the octahedral coordination in the original complexes. The green-red-green interconversions observed in the series of conducted experiments $\left(\mathbf{1} \rightarrow \mathbf{3} \rightarrow \mathbf{1}^{\mathbf{1}} \ldots\right)$ were assigned to the reversible release and reabsorption of the solvent and to reversible change of coordination around $\mathrm{Ni}^{\mathrm{II}}$ from six to four. However, not all $\mathrm{Ni}^{\mathrm{II}}$ ions come to the diamagnetic state, possibly due to the remaining disorder around some nickel ions preventing against the ideal surrounding needed for transition to low spin. The observed downturn of $\chi T$ with the lowering of the temperature is similar in all compounds. This decrease is coming from the zero-field splitting. ${ }^{29}$ Susceptibility of a series of samples obtained after successive exposure to water vapors and recycling in methanol vapors alternately is shown in Fig. 7 (for 2 Fig. S33, ESI $\dagger$ ).

In the case of the water-methanol cycle, $\mathbf{1} \rightarrow 3^{\mathbf{w}} \rightarrow \mathbf{1}^{\mathbf{1}} \rightarrow 3^{\mathbf{w 1}} \rightarrow$ $\mathbf{1}^{2} \rightarrow 3^{\mathrm{w} 2} \rightarrow \mathbf{1}^{3} \rightarrow 3^{\mathrm{w} 3}$, the decrease of Curie constant and Weiss parameter values after exposure to water vapors is less expressed than in the case of the heat-methanol cycle. Exposure of 1 to water vapors leads to some more complex mixed state in the sense that it is not saturated, but magnetization is still higher than expected for
Table 1 Effective exchange interaction parameters $J, g$-factors, and percentage $p$ of the remaining $S=1$ ions for 1 in both cycles: heatmethanol $\left(1 \rightarrow 3 \rightarrow 1^{1} \rightarrow 3^{1} \rightarrow 1^{2} \rightarrow 3^{2} \rightarrow 1^{3} \rightarrow 3^{3}\right)$ and water-methanol $\left(1 \rightarrow 3^{\mathrm{w}} \rightarrow 1^{1} \rightarrow 3^{\mathrm{w} 1} \rightarrow 1^{2} \rightarrow 3^{\mathrm{w} 2} \rightarrow 1^{3} \rightarrow 3^{\mathrm{w} 3}\right)$

\begin{tabular}{|c|c|c|c|c|c|c|}
\hline \multirow[b]{2}{*}{ Step } & \multicolumn{3}{|c|}{$\begin{array}{l}\text { Heat-methanol cycle } \\
\text { of cluster } 1\end{array}$} & \multicolumn{3}{|c|}{$\begin{array}{l}\text { Water-methanol cycle } \\
\text { of cluster } 1\end{array}$} \\
\hline & $J / \mathrm{K}$ & $G$ & $p / \%$ & $J / \mathrm{K}$ & $g$ & $p / \%$ \\
\hline 1 & $4.53(5)$ & $2.31(1)$ & 100 fixed & $4.53(5)$ & 2.31 fixed & $99.7(2)$ \\
\hline $3 / 3^{w}$ & $1.2(2)$ & 2.33 fixed & $23.4(6)$ & $2.1(1)$ & 2.31 fixed & $91.8(8)$ \\
\hline $1^{1} / 1^{1}$ & $3.55(5)$ & $2.46(1)$ & 100 fixed & $3.1(1)$ & 2.31 fixed & $95.2(3)$ \\
\hline $3^{1} / 3^{w 1}$ & $0.3(1)$ & 2.33 fixed & $50.5(8)$ & $2.6(1)$ & 2.31 fixed & $76.9(4)$ \\
\hline $1^{2} / 1^{2}$ & $2.70(4)$ & $2.29(1)$ & 100 fixed & $6.0(2)$ & 2.31 fixed & $84.1(3)$ \\
\hline $3^{2} / 3^{w 2}$ & $0.8(1)$ & 2.33 fixed & $64(1)$ & $2.4(2)$ & 2.31 fixed & $71.7(4)$ \\
\hline $1^{3} / 1^{3}$ & $3.71(6)$ & $2.26(1)$ & 100 fixed & $4.4(2)$ & 2.31 fixed & $83.8(2)$ \\
\hline $3^{3} / 3^{w 3}$ & $0.8(1)$ & 2.33 fixed & $40.1(8)$ & $2.8(3)$ & 2.31 fixed & $33.9(2)$ \\
\hline
\end{tabular}

independent ions. Quantitative analysis of these data is not practical since there are many possible combinations of partial transitions within cubanes, making the fitting procedure overparameterized and impossible to perform. However, the observations are informative enough to help in explaining the magnetic changes within the light of solvatomagnetic effects.

Effective exchange interaction parameters $J, g$-factors, and percentage $p$ of the remaining $S=1$ ions for cluster 1 (for 2 Table S10, ESI $\dagger$ ) in both cycles are given in Table 1 . The obtained values of $J$ are in accordance with similar structures, ${ }^{29}$ where similar corresponding angles within the Ni4 core were reported. Since the maximum of susceptibility is reached at $3.8 \mathrm{~K}$ resulting from the exchange coupling of cubane, and the $\mathrm{M}(\mathrm{H})$ dependence is reversible and linear for small fields down to $2 \mathrm{~K}$, there is no possibility to observe SMM phenomena under investigated conditions, as was the case in other Ni4. ${ }^{29}$

More details about modelling of magnetic behaviour as well as the corresponding results of the equivalent series of compound 2 are presented in the ESI. $\dagger$

\section{Quantum chemical calculations}

Geometry optimizations for the $\left[\mathrm{Ni}_{4} \mathrm{~L}_{4}\left(\mathrm{CH}_{3} \mathrm{OH}\right)_{4}\right]$ cluster and its modeled derivative were performed using the density functional theory with two hybrid functionals B3LYP and MN12SX. Calculations started from the experimentally determined crystal structures of compounds $1 \mathbf{a}$ and $\mathbf{2 a}$ ( $C_{2}$ point group of symmetry). In each case, all calculated geometrical parameters were very similar to the experimental ones, thus confirming the validity of the methods chosen. In order to investigate how the lattice solvent affects the magnetic properties of the compound, models of the $\left[\mathrm{Ni}_{4} \mathrm{~L}_{4}\left(\mathrm{CH}_{3} \mathrm{OH}\right)_{4}\right]$ cluster with a toluene molecule placed near the phenyl ring of the ligand $\left(\mathrm{L}^{2-}=\mathrm{C}_{6} \mathrm{H}_{5}(\mathrm{O})-\mathrm{C}=\mathrm{N}-(\mathrm{O}) \mathrm{C}_{6} \mathrm{H}_{4} \mathrm{CH}_{3}\right)$ were constructed (Fig. 8). Since the only experimentally observable difference between unit cells of $\mathbf{1}$ and $\mathbf{1 a}$ in comparison with $\mathbf{2}$ and 2a was essentially a slight change in the $\mathrm{C}-\mathrm{H}-\pi$ distance (Fig. 2), a toluene molecule was placed in two different positions, mimicking the crystal structures of $\mathbf{1}$ and $\mathbf{2}$ (Fig. 8). After a series of geometry optimizations, no significant geometrical change in the $\left(\mathrm{Ni}^{\mathrm{iI}}\right)_{4}$ core could be observed in either of the models. Natural bond orbital (NBO) analyses performed on each structure revealed that the 

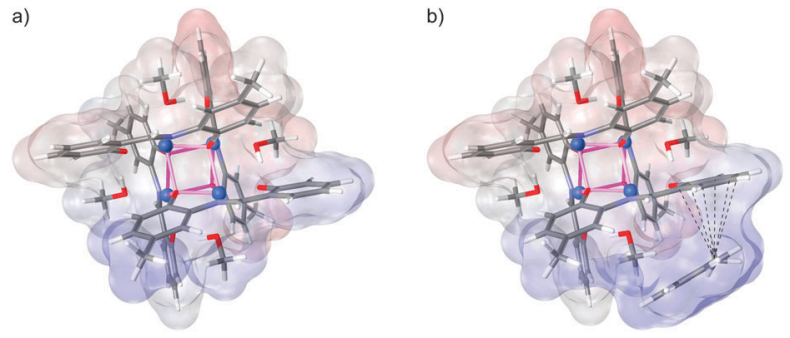

Fig. 8 Optimized geometries of (a) $\left[\mathrm{Ni}_{4} \mathrm{~L}_{4}\left(\mathrm{CH}_{3} \mathrm{OH}\right)_{4}\right]\left(\mathrm{C}_{2}\right.$ point group of symmetry) and (b) the complex of $\left[\mathrm{Ni}_{4} \mathrm{~L}_{4}\left(\mathrm{CH}_{3} \mathrm{OH}\right)_{4}\right]$ with toluene (B3LYP/ 6-31G(d) level of theory); interatomic distances frozen during optimizations are given using dashed lines and the solvent accessible surface is displayed. ${ }^{36}$ The other complex with slightly shifted toluene molecules is not presented here.

change in the Ni-solvent distance has a negligible effect on the NBO occupancies of nickel atoms (Tables S11-S14, ESI $\dagger$ ). Consequently, the observed differences in magnetic properties are most probably not caused by minor changes within the unit cells of $\mathbf{1}$ and $\mathbf{1 a}$ in comparison with $\mathbf{2}$ and $\mathbf{2 a}$, but are due to the different solvent disorder acting as an outer electrostatic potential for the $\left(\mathrm{Ni}^{\mathrm{II}}\right)_{4}$ core.

\section{Conclusions}

Two starting compounds, $\left[\mathrm{Ni}_{4} \mathrm{~L}_{4}\left(\mathrm{CH}_{3} \mathrm{OH}\right)_{4}\right] \cdot 0.32 \mathrm{CH}_{3} \mathrm{OH} \cdot 0.32 \mathrm{H}_{2} \mathrm{O}$ (1) and $\left[\mathrm{Ni}_{4} \mathrm{~L}_{4}\left(\mathrm{CH}_{3} \mathrm{OH}\right)_{4}\right] \cdot 0.63 \mathrm{CH}_{3} \mathrm{OH}$ (2), L $\mathrm{L}^{2-}$ ( $N$-(2-hydroxy-5methylphenyl)salicylideneiminato anion), and various transition paths were used to generate a range of $\mathrm{Ni}_{4} \mathrm{~L}_{4}$ clusters, differing in the type and amount of incorporated solvent. (Inter)conversions of coordinated and non-coordinated solvents and their effect on the magnetic and structural properties were examined. Exposing clusters (1) and (2) to room temperature resulted in a slight colour change, caused by the loss of non-coordinated solvates (1a and 2a). Annealing of these compounds yielded cluster $3,\left[\mathrm{Ni}_{4} \mathrm{~L}_{4}\right]$. Loss of the coordinated solvent caused the colour to be changed to red, and a partial transition of the spin of $\mathrm{Ni}^{\mathrm{II}}$ ions from the ground state from $S=1$ to $S=0$. This partial transition could be assigned to temperature-induced disorder of the $\mathrm{Ni}_{4} \mathrm{~L}_{4}$ core in the material. Several cycles of annealing- $\mathrm{MeOH}$ sorption experiments showed that the process is not fully reversible. Namely, the geometry of the $\mathrm{N}_{4} \mathrm{~L}_{4}$ core was shown to vary, and materials obtained by sorption processes were also found to differ, probably in the amount of non-coordinated solvent. Similarly, a series of experiments where compounds 1 and $\mathbf{2}$ were consecutively exposed to $\mathrm{H}_{2} \mathrm{O}$ and $\mathrm{CH}_{3} \mathrm{OH}$ vapors showed differences in their powder diffraction patterns. This indicated that the number and amount of coordinated and non-coordinated solvents can vary, and are not easy to predict. Moreover, according to the quantum-mechanical calculations, it is the disorder that plays an important role in determining magnetic properties of the material. Existence of mixed solvates, and statistical and dynamic disorder of solvent molecules presented here indicate that there are multiple risks in the design of materials with desired magnetic properties: (i) fully controlled synthesis, (ii) establishing the exact magneto-structural relationship, (ii) water/methanol ambiguity, and (iii) stability of synthesised products. Detailed interpretation of the structural and magnetic correlation remains a challenge for future studies of these systems.

\section{Experimental}

\section{Synthesis and materials}

All chemicals obtained from commercial sources were analytically pure and were used without further purification. The Schiff base $N$-(2-hydroxy-5-methylphenyl)salicylideneimine was prepared according to the literature data. ${ }^{37}$

(a) Cluster 1 was prepared from $\mathrm{Ni}\left(\mathrm{O}_{2} \mathrm{CMe}\right)_{2} \cdot 4 \mathrm{H}_{2} \mathrm{O}(1 \mathrm{mmol})$ and Schiff base $(1 \mathrm{mmol})$ in methanol $(20 \mathrm{~mL})$. The reactants were sealed in a $50 \mathrm{~mL}$ Teflon-lined, stainless-steel bomb. The bomb was heated at $110{ }^{\circ} \mathrm{C}$ for 1.5 hour. The obtained green plate-like single crystals were collected by filtration and washed with a minimum amount of cold methanol. Yield 51\%: anal. calcd (without lattice solvent) (\%) for $\mathrm{C}_{60} \mathrm{H}_{60} \mathrm{~N}_{4} \mathrm{Ni}_{4} \mathrm{O}_{12}$ (1a): C, 57.02; H, 4.78; N, 4.43; Ni, 18.57. Found: C, 56.92; H, 4.82; N, 4.01; Ni, 18.19 .

(b) The same crystalline product 1 was obtained using a similar procedure as in (a), in the solvent mixture of methanol $(20 \mathrm{~mL})$ and water $(5 \mathrm{~mL})$. The green plate-like crystalline product of 1 was not obtained if acetic anhydride $(1 \mathrm{~mL})$ was added to the reaction mixture of $\mathrm{Ni}\left(\mathrm{O}_{2} \mathrm{CMe}\right)_{2} \cdot 4 \mathrm{H}_{2} \mathrm{O}(1 \mathrm{mmol})$ and Schiff base $(1 \mathrm{mmol})$ in dry methanol $(20 \mathrm{~mL})$ and using a similar procedure as in (a).

(c) Cluster 2 was prepared by mixing the methanolic solutions of $\mathrm{Ni}\left(\mathrm{O}_{2} \mathrm{CMe}\right)_{2} \cdot 4 \mathrm{H}_{2} \mathrm{O}(1 \mathrm{mmol}$ in $10 \mathrm{~mL})$ and Schiff base $(1 \mathrm{mmol}$ in $10 \mathrm{~mL}$ ) at room temperature. After two days, green, prismatic single crystals were obtained. Yield 58\%: anal. calcd (without lattice solvent) (\%) for $\mathrm{C}_{60} \mathrm{H}_{60} \mathrm{~N}_{4} \mathrm{Ni}_{4} \mathrm{O}_{12}$ (2a): C, 57.02; $\mathrm{H}, 4.82 ; \mathrm{N}$, 4.43; Ni, 18.57. Found: C, 56.70; H, 4.80; N, 4.29; Ni, 18.50.

(d) The same crystalline product 2 was obtained using a similar procedure as in (a) in the mixture of dry methanol $(20 \mathrm{~mL})$ and acetic anhydride $(1 \mathrm{~mL})$.

(e) Cluster 3, as dark red prisms or plates, was obtained after removal of the solvent molecules (coordinated and solvated) of 1 or 2 at $180{ }^{\circ}$ C. Anal. calcd (\%) for $\mathrm{C}_{56} \mathrm{H}_{44} \mathrm{~N}_{4} \mathrm{Ni}_{4} \mathrm{O}_{8}$ (3): C, 59.22; $\mathrm{H}$, 3.91; N, 4.93; Ni, 20.67. Found: C, 59.10 H, 3.79; N, 4.64; Ni, 20.82.

IR spectroscopy. IR spectra were recorded on a PerkinElmer Spectrum RXI FT-IR spectrometer ( $\mathrm{KBr}$ pellet technique, 4000$400 \mathrm{~cm}^{-1}$ range, $2 \mathrm{~cm}^{-1}$ step, Fig. S34-S39, ESI $\left.\dagger\right)$.

Cluster 1: 3406(b,m), 3056(m), 3007(m), 2917(m), 2793(m), 1604(vs), 1531(s), 1490(vs), 1378(m), 1305(s), 1226(s), 1127(s), 1034(m), 825(s), 750(s), 522(m).

Cluster 2: 3385(w), 3006(m), 2920(m), 2792(m), 2341(w), 2189(w), 1603(vs), 1531(s), 1490(vs), 1378(m), 1306(s), 1223(s), 1145(s), 1031(m), 824(s), 751(s), 524(m).

Cluster 3: 3054(m), 2915(m), 2359(m), 1599(vs), 1532(s), 1464(s), 1377(m), 1280(s), 1221(s), 1147(s), 1125(m), 828(s), 751(s), 668(m).

TGA and DSC experiments. The thermal analyses were carried out on Mettler Toledo TGA/SDTA 851 and DSC823 
modules in sealed aluminium pans $(40 \mu \mathrm{L})$, by heating in a flow of nitrogen or oxygen $\left(200 \mathrm{~mL} \mathrm{~min}{ }^{-1}\right)$ at 5 or $10{ }^{\circ} \mathrm{C} \mathrm{min}{ }^{-1}$. The data collection and analyses were performed using the program package STARe Software 9.01. ${ }^{38}$

Chromatography. The content of methanol and water was determined using Headspace-GC system Agilent Technologies 7890 and Metrohm $831 \mathrm{KF}$ coulometer, respectively.

Calcd for cluster 1: $\mathrm{CH}_{3} \mathrm{OH} 10.85 ; \mathrm{H}_{2} \mathrm{O} 0.45 \%$; found: $\mathrm{CH}_{3} \mathrm{OH}$ 9.89; $\mathrm{H}_{2} \mathrm{O} 0.36 \%$.

Calcd for cluster 2: $\mathrm{CH}_{3} \mathrm{OH}$ 11.63; found: $\mathrm{CH}_{3} \mathrm{OH} 11.10 \%$.

DVS experiments. The water sorption isotherms were measured using an accurate humidity and temperature-controlled microbalance system, Dynamic Vapour Sorption (DVS 1, Surface Management Systems, UK). The relative humidity (RH) was increased in steps from 0 to $90 \%$ and back to $0 \%$ at $26{ }^{\circ} \mathrm{C}$. The equilibration condition at each step of the $\mathrm{RH}$ for the rate of change in mass with time $(\mathrm{d} m / \mathrm{d} t)$ was selected (Fig. S25 and S26, Tables S8 and S9, ESI $\dagger$ ).

Magnetic studies. All compounds in the form of crushed single crystalline samples were measured using a commercial MPMS5 SQUID magnetometer. Contribution of ampoule was subtracted properly and the susceptibility was corrected with respect to the temperature independent diamagnetic and paramagnetic contributions. Temperature dependence of magnetic susceptibility was calculated from measurements in $0.1 \mathrm{~T}$ magnetic field. Field dependence of magnetization was measured at several temperatures in order to complement the susceptibility analysis.

Single crystal X-ray crystallography. The selected geometries including valence bonds of each $\mathrm{Ni}^{\mathrm{II}}$ coordination sphere, $\mathrm{Ni} \cdots \mathrm{Ni}$ distances, the comprehensive hydrogen bond geometry, $\mathrm{C}-\mathrm{H} \cdots \pi$ interactions and some dihedral angles are given (Tables S1-S5, ESI $\dagger$ ). The data collection was performed by applying the CrysAlis Software system, Version 1.171.32.24, ${ }^{39}$ on the Oxford Xcalibur diffractometer equipped with a CCD detector and using graphite-monochromated $\operatorname{MoK} \alpha$ radiation $(\lambda=0.71703 \AA)$ at $296 \mathrm{~K}$ (1a and $2 \mathrm{a})$ and $150 \mathrm{~K}$ (1 and 2) and $\omega$-scans. The programs CrysAlis CCD and CrysAlis RED (Version 1.171.33.41) ${ }^{39}$ were employed for data collection, cell refinement and data reduction. The Lorentz-polarization effect was corrected and the diffraction data were scaled for absorption effects by the multiscanning method. Structures were solved by direct methods and refined on F2 by weighted full-matrix least-squares. The programs SHELXL-2014 ${ }^{40}$ and the WinGX v. $1.80 .05^{41}$ software system were used to solve and refine structures. All non-hydrogen atoms were refined using the anisotropic displacement parameters. The solvent content in $\mathbf{1}$ and $\mathbf{2}$ was crystallographically modelled. The solvent molecules are found to be present in the lowtemperature crystal structures with the partial occupancy factors of atoms $\left(\mathrm{H}_{2} \mathrm{O} / \mathrm{MeOH}=0.32: 0.32\right.$ in $\mathbf{1}$ and 0.63 in 2), which have been refined as free variables, but at the final least-square refinement cycle, in order to obtain the final molecular formulae, the occupancies were fixed. By using SUMP instructions the sum of the occupancies of the two possible oxygen positions O5A and O5B in 2 was constrained to 0.63 . The hydrogen atoms belonging to the stereochemically different carbon atoms and due to the data collection temperature were placed in the geometrically idealized positions with assigned isotropic displacement parameters and they were constrained to ride on their parent atoms by using the appropriate SHELXL-2014 HFIX instructions. The hydrogen atoms belonging to the coordinated methanol molecules were firstly found in the difference Fourier maps at the final stages of the refinement procedure and then refined by SHELXL-2014 DFIX instructions at 0.82(1) $\AA$ and 0.84(1) $\AA$ (for 1a and 2a compounds at $296 \mathrm{~K}$ and for 1 and 2 at $150 \mathrm{~K}$, respectively) with assigned isotropic displacement parameters being 1.2 times larger than the equivalent isotropic displacement parameters of the parent oxygen atoms. The hydrogen atoms which belong to the methyl group of the solvent methanol molecule (or water) are not modelled. The molecular geometry calculations and graphics were done using ORTEP-III ${ }^{42}$ integrated in the WinGX software system, PLATON ${ }^{43}$ programme and Mercury. ${ }^{44}$ Supplementary crystallographic data (atomic coordinates, thermal parameters, all intramolecular distances and angles for all structures) are given in the ESI $\dagger$ (in the CIF format).

X-ray powder diffraction (XRPD). All X-ray powder diffraction (XRPD) experiments of the samples were performed on a PHILIPS PW 1840 X-ray diffractometer with $\mathrm{CuK} \alpha_{1}(1.54056 \AA)$ radiation at $40 \mathrm{~mA}$ and $40 \mathrm{kV}$. The scattered intensities were measured using a scintillation counter. The angular range $(2 \theta)$ was from 3 to $50^{\circ}$ with steps of $0.02^{\circ}$, and the measuring time was $0.5 \mathrm{~s}$ per step. The data collection and analysis were performed using the program package Philips X'Pert. ${ }^{45,46}$ Structural analysis of compound 3 involved several XRPD patterns. Initially, two materials, one obtained by heating compound $\mathbf{1}$ and the other obtained by heating compound 2, were measured. Although comparison of these two patterns revealed a poorly crystalline substance, these two patterns were not the same. This suggested that the molecular moieties in these two materials have different arrangements.

For the purpose of structure determination of cluster 3 , a fresh sample of cluster 1a was produced, and then heated up to $180{ }^{\circ} \mathrm{C}$. This sample was first examined under the microscope, which revealed small crystals with cracked surfaces, resembling a deposit of many thin platelets closely stacked together (Fig. S40, ESI $\dagger$ ). Grinding the sample in the mortar resulted in paste-like material that was filled in a $1 \mathrm{~mm}$ capillary. X-ray powder diffraction (XRPD) data were measured using the MYTHEN detector ${ }^{47}$ installed at the Swiss Light Source, ${ }^{48}$ using an X-ray energy of $17.7 \mathrm{keV}(0.7012 \AA)$. Any radiation damage was avoided by collecting $120^{\circ}$ of data within ten seconds (Table S15, ESI $\dagger$ ). The measured XRPD pattern showed only a few sharp peaks and several broad ones, resulting in low data resolution $\left(d_{\min }=3 \AA\right)$. The XRPD pattern was compared to the calculated patterns of $\mathbf{1 a}(\mathbf{2 a})$, and observed similarities led to the conclusion that these structures are correlated. Therefore, unit cell parameters of 1a (2a) were used to facilitate the indexing of the pattern of cluster 3 , and the starting model of the $\left[\mathrm{Ni}_{4} \mathrm{~L}_{4}\right]$ cluster could be built using the structural information of 1a (2a). Considering that magnetic measurements of cluster 3 revealed antiferromagnetic properties, a planar-square geometry of the $\left[\mathrm{Ni}_{4} \mathrm{~L}_{4}\right]$ cluster was expected. In order to construct such a molecular structure, coordinated methanol from the 1a structure was removed (Fig. 3a, (a)), and this model was subjected to a 
series of energy optimizations ${ }^{49}$ (for details, see Computational methods). As expected, all calculations resulted in clusters of four square-planar coordinated Ni-centers, with $\mathrm{Ni}-\mathrm{O}-\mathrm{Ni}$ angles larger than $99^{\circ}$, suggesting the antiferromagnetic properties of the molecule (Fig. 3b, (b)). ${ }^{24,29}$ This molecular structure and unit cell parameters calculated from XRPD data were used as input for the crystal structure determination program FOX, based on direct-space optimization. ${ }^{50}$ Although all investigated samples $(\mathbf{1}, \mathbf{2}, \mathbf{1 a}$, and 2a) exhibited $P \overline{1}$ symmetry, direct-space optimization processes were carried out in $P 1$ symmetry without any restraints, in order to minimize model bias. However, this approach resulted in chemically non-reasonable structures. The reason for this failure was sought in the preferred orientation of the crystals, resulting in incorrect assignment of the relative intensities of the peaks. This obstacle was overcome by employing soft geometrical restraints. This way, solutions with chemically reasonable intermolecular distances could be favored. The obtained crystal structure of cluster 3 was subjected to Rietveld refinement, using the XRS suite of programs. ${ }^{51}$ Considering that insufficient data resolution did not allow for refinement of the atomic coordinates, only non-structural parameters (peak shapes and positions, zero shift, sample displacement, and scale) were refined (Fig. 4 and Table S15, ESI $\dagger$ ). Subsequently, the geometry of the resulting crystal structure was optimized using the quantum mechanical approach (Fig. S41a, ESI $\dagger$ ). Comparison between the optimized (ideal) molecular structure and the molecular structure obtained from FOX (average) is given in Fig. S41b (ESI $\dagger$ ). All discrepancies between two models are considered to be a consequence of disorder in the material.

Computational methods. Quantum chemical calculations (compounds 1 and 2, toluene model) were carried out using the Gaussian 09 program package. ${ }^{52}$ Geometry optimization of ground states was performed using hybrid functionals B3LYP ${ }^{53,54}$ and $\mathrm{MN} 12 \mathrm{SX}^{55}$ in combination with the 6-31G(d) basis set. For all optimized structures harmonic frequencies were calculated to ensure that the obtained geometries correspond to the minimum on the potential energy surface. To simulate the influence of packing within the unit cell, models containing the $\left[\mathrm{Ni}_{4} \mathrm{~L}_{4^{-}}\right.$ $\left.\left(\mathrm{CH}_{3} \mathrm{OH}\right)_{4}\right]$ complex and a toluene molecule were built. In each of the two separate models the toluene molecule was placed in a different position near the phenyl ring of $\mathrm{L}$ and interatomic distances between the carbon atom of the toluene's methyl group and carbon atoms of the phenyl ring were fixed during the optimization. Natural bond orbital (NBO) analysis ${ }^{52}$ on all optimized structures was conducted using the Gaussian 09 . $A b$ initio calculations for structure determination of compound 3 were performed within the framework of density functional theory (DFT) as implemented in the VASP code $^{56}$ using the projector augmented wave (PAW) method. ${ }^{57}$ We have used the self-consistently implemented $\mathrm{vdW}-\mathrm{DF}^{58,59}$ functional for correlation in combination with optB88 exchange. In all calculations the expansion in plane waves was done using the cut-off energy of $750 \mathrm{eV}$. The Brillouin zone was sampled by the Monkhorst-Pack choice of $k$-points, namely $2 \times 1 \times 1$. The atoms were allowed to relax until the forces on them were below $1 \mathrm{meV}^{-1}$.

\section{Acknowledgements}

Financial support for this research was provided by the Ministry of Science and Technology of the Republic of Croatia.

\section{References}

1 (a) C.-M. Ji, H.-J. Yang, C.-C. Zhao, V. Tangoulis, A.-L. Cui and H.-Z. Kou, Cryst. Growth Des., 2009, 9, 4607-4609; (b) A. O. Polyakov, A. H. Arkenbout, J. Baas, R. G. Blake, A. Meetsma, A. Caretta, P. H. M. van Loosdrecht and T. T. M. Palstra, Chem. Mater., 2012, 24, 133-139; (c) S. Osa, T. Kido, N. Matsumoto, N. Re, A. Pochaba and J. Mrozinski, J. Am. Chem. Soc., 2004, 126, 420-421.

2 H.-Z. Kou, G.-Y. An, C.-M. Ji, B.-W. Wang and A.-L. Cui, Dalton Trans., 2010, 39, 9604-9610.

3 C. Papatriantafyllopoulou, L. F. Jones, T. D. Nguyen, N. Matamoros-Salvador, L. Cunha-Silva, F. A. Paz, J. Rocha, M. Evangelisti, E. K. Brechen and S. P. Perlepes, Dalton Trans., 2008, 3153-3155.

4 E. Pardo, R. Ruiz-García, J. Cano, X. Ottenwaelder, R. Lescouëzec, Y. Journaux, F. Lloret and M. Julve, Dalton Trans., 2008, 2780-2805.

5 A. J. Zhou, J. L. Liu, R. Herchel, J. D. Leng and M. L. Tong, Dalton Trans., 2009, 3182.

6 P. King, R. Clerac, W. Wernsdorfer, E. C. Anson and A. K. Powell, Dalton Trans., 2004, 2670-2767.

7 R.-X. Yao, X. Xu and X.-M. Zhang, Chem. Mater., 2012, 24, 303-310.

8 G.-Y. An, C.-M. Ji, A.-L. Cui and H.-Z. Kou, Inorg. Chem., 2011, 50, 1079-1083.

9 I. S. Tidmarsh, E. Scales, P. R. Brearley, J. Wolowska, L. Sorace, A. Caneschi, R. H. Laye and E. J. L. McInnes, Inorg. Chem., 2007, 46, 9743-9753.

10 S. L. Castro, Z. Sun, C. M. Grant, J. C. Bollinger, D. N. Hendrickson and G. Christou, J. Am. Chem. Soc., 1998, 120, 2365-2375.

11 E.-C. Yang, W. Wernsdorfer, S. Hill, R. S. Edwards, M. Nakano, S. Maccagnano, L. N. Zakharov, A. L. Rheingold, G. Christou and D. N. Hendrickson, Polyhedron, 2003, 22, 1727-1733.

12 M. Moragues-Cánovas, M. Helliwell, L. Ricard, E. Riviere, W. Wernsdorfer, E. Brechin and T. Mallah, Eur. J. Inorg. Chem., 2004, 2219-2222.

13 (a) Y. Guo, L. Li, Y. Liu, Y. Dong and D. Wang, Acta Crystallogr., Sect. E: Struct. Rep. Online, 2008, 64, m675-m676; (b) K. Ayikoe, R. J. Butcher and Y. Gultneh, Acta Crystallogr., Sect. E: Struct. Rep. Online, 2010, E66, m1487-m1488.

14 P. Chanduri, V. Kataev, B. Büchner, H.-H. Klaus, B. Kersting and F. Meyer, Coord. Chem. Rev., 2009, 253, 2261-2285.

15 J. M. Clemente-Juan, B. Chansou, B. Donnadieu and J.-P. Tuchagues, Inorg. Chem., 2000, 39, 5515-5519.

16 M. A. Palacios, A. J. Mota, J. E. Perea-Buceta, F. J. White, E. K. Brechin and E. Colacio, Inorg. Chem., 2010, 49, 10156-10165. 
17 M. S. El Fallah, E. Rentschler, A. Caneschi and D. Gatteschi, Inorg. Chim. Acta, 1996, 247, 231-235.

18 M. Mikuriya, K. Minowa and N. Nagao, Inorg. Chem. Commun., 2001, 4, 441-443.

19 (a) J.-W. Ran, S.-Y. Zhang, B. Xu, Y. Xia, D. Guo, J.-Y. Zhang and Y. Li, Inorg. Chem., 2008, 11, 73-76; (b) Q. Liang, R. Huang, X. Chen, Z. Li, X. Zhang and B. Sun, Inorg. Chem. Commun., 2008, 11, 73-76; (c) J.-P. Sun, L.-C. Li and X.-J. Zheng, Inorg. Chem. Commun., 2011, 14, 877-881.

20 A. Escuer, M. Font-Bardía, S. B. Kumar, X. Solans and R. Vicente, Polyhedron, 1999, 909-914.

21 A. Sieber, C. Boskovic, R. Bircher, O. Waldmann, S. T. Ochsenbein, G. Chabonssant, W. Wernsdorfer, A. Neels, H. Stockli-Evans, S. Janssen, F. Juranyi and H. Mutka, Inorg. Chem., 2005, 44, 4315-4325.

22 M. A. Halcrow, J. S. Sun, J. C. Huffman and G. Christou, Inorg. Chem., 1995, 34, 4167-4177.

23 S.-Y. Zhang, W.-Q. Chen, B. Hu, Y.-M. Chen, W. Li and Y. Li, Inorg. Chem. Commun., 2012, 16, 74-77.

24 J. A. Bertrand, C. Marabella and D. G Vanderveer, Inorg. Chim. Acta, 1978, 26, 113-118.

25 W. L. Gladfelter, M. W. Lynch, W. P. Schaefer, D. N. Hendrickson and H. B. Gray, Inorg. Chem., 1981, 20, 2390-2397.

26 L. Ballester, E. Coronado, A. Gutierrez, A. Monge, M. F. Perpinan, E. Pinilla and T. Rico, Inorg. Chem., 1992, 31, 2053-2056.

27 S. Petit, P. Neugebauer, G. M. Pilet, G. Chastanet, A.-L. Barra, A. B. Autunes, W. Wernsdorfer and D. Lunean, Inorg. Chem., 2012, 51, 6645-6654.

28 (a) O. Kahn and J. V. Larinova, Chem. - Eur. J., 1999, 5, 3443-3449; (b) H. Zheng-Ming and X.-M. Zhang, Dalton Trans., 2011, 40, 2092-2098.

29 (a) A. Das, F. J. Klinke, S. Demeshko, S. Meyer, S. Dechert and F. Meyer, Inorg. Chem., 2012, 51, 8141-8149; (b) P. S. Perlepe, A. A. Athanasopoulou, K. I. Alexopoulou, C. P. Raptopoulou, V. Psycharis, A. Escuer, S. P. Perlepes and T. C. Stamatatos, Dalton Trans., 2014, 43, 16605-16609; (c) S. Karmakar and S. Khanra, CrystEngComm, 2014, 16, 2371-2383; (d) G. Aromi, E. Bouwman, E. Burzuri, C. Carbonera, J. Krzystek, F. Luis, C. Schlegel, J. van Slageren, S. Tanase and S. J. Teat, Chem. - Eur. J., 2008, 14, 11158-11166.

30 G. Redler, C. Lampropoulos, S. Datta, C. Koo, T. C. Stamatatos, N. E. Chakov, G. Christou and S. Hill, Phys. Rev., 2009, B80, 094401.

31 Y.-Y. Zhu, T.-T. Yin, S.-D. Jiang, A.-L. Barra, W. Wernsdorfer, P. Neugebauer, R. Marx, M. Dörfel, B.-W. Wang, Z.-Q. Wu, J. van Slageren and S. Gao, Chem. Commun., 2014, 50, 15090-15093.

32 (a) A. Masello, K. A. Abboud, W. Wernsdorfer and G. Christou, Inorg. Chem., 2013, 52, 10414-10423; (b) F.-P. Huang, C. Yang, H.-Y. Li, P.-F. Yao, X.-H. Qin, S.-P. Yan and M. Kurmoo, Dalton Trans., 2015, 44, 6593-6599; (c) X. Zhang, V. Vieru, X. Feng, J.-L. Liu, Z. Zhang, B. Na, W. Shi, B.-W. Wang, A. K. Powell, L. F. Chibotaru, S. Gao, P. Cheng and J. R. Long, Angew. Chem., Int. Ed., 2015, 54, 9861-9865.

33 (a) T. Steiner, Angew. Chem., Int. Ed., 2002, 41, 48-76; (b) G. R. Desiraju and T. Steiner, The Weak Hydrogen Bond,
IUCr monographs on crystallography, Oxford University Press, Great Clarendon Street, Oxford OX2 6DP, UK, 2001, pp. 29-120.

34 (a) M. A. Spackman and D. Jayatilaka, CrystEngComm, 2009, 11, 19-32; (b) S. K. Wolff, D. J. Grimwood, J. J. McKinnon, M. J. Turner, D. Jayatilaka and M. A. Spackman, CrystalExplorer (Version 3.0), University of Western Australia, Perth, 2012; (c) M. A. Spackman and J. J. McKinnon, CrystEngComm, 2002, 4, 378-392; (d) www.povray.org.

35 (a) J. A. Bertrand, A. P. Ginsberg, R. I. Kaplan, C. E. Kirkwod, R. L. Martin and R. C. Sherwod, Inorg. Chem., 1971, 10, 240-246; (b) E. K. Barefield, D. H. Busch and S. M. Nelson, Q. Rev., 1968, 22, 457-498.

36 http://www.accelrys.com/.

37 M. Cindrić, N. Strukan, V. Vrdoljak, T. Kajfež and B. Kamenar, Z. Anorg. Allg. Chem., 2002, 628(9-10), 2113-2117.

$38 S_{\text {STAR }}^{e}$ Software V.9.01., Mettler Toledo GmbH, 2006.

39 Oxford Diffraction Ltd., Xcalibur CCD system, CrysAlis Software system, Versions 1.171.32.24 and 1.171.33.41. Abingdon; Oxfordshire, England, 2008.

40 (a) G. M Sheldrick, A short history of SHELX., Acta Crystallogr., Sect. A: Found. Crystallogr., 2008, 64, 112-122; (b) G. M Sheldrick, SHELXL-2014, Acta Crystallogr., Sect. C: Struct. Chem., 2015, 71, 3-8A.

41 L. J. Farrugia, WinGX (Ver. 1.80.05) suite for small-molecule single-crystal crystallography, J. Appl. Crystallogr., 1999, 32, 837-838.

42 L. J. Farrugia, Ortep-3 for Windows (v. 2.02) - a version of the current release of ORTEP-III, which incorporates a Graphical User Interface (GUI), J. Appl. Crystallogr., 1997, 30, 565 .

43 L. Spek, A Multipurpose Crystallographic Tool, J. Appl. Crystallogr., 2003, 36, 7-13.

44 C. F. Macrae, I. J. Bruno, J. A. Chisholm, P. R. Edgington, P. McCabe, E. Pidcock, L. Rodriguez-Monge, R. Taylor, J. van de Streek and P. A. Wood, Mercury CSD 2.0 - new features for the visualization and investigation of crystal structures, J. Appl. Crystallogr., 2008, 41, 466-470.

45 Philips X'Pert Data Collector 1.3e, Philips Analytical B. V. Netherlands, 2001.

46 Philips X'Pert Plus 1.0, Philips Analytical B. V. Netherlands, 1999.

47 B. Schmitt, C. Brönnimann, E. Eikenberry, F. Gozzo, C. Hörmann, R. Horisberger and B. Patterson, Nucl. Instrum. Methods Phys. Res., 2003, A501, 267-272.

48 P. R. Willmott, D. Meister, S. J. Leake, M. Lange, A. Bergamaschi, M. Böge, M. Calvi, C. Cancellieri, N. Casati, A. Cervellino, Q. Chen, C. David, U. flechsig, F. gozzo, B. Henrich, S. Jäggi-Spielmann, B. Jakob, I. Kalichava, P. Karvinen, J. Krempasky, A. Lüdeke, R. Lüscher, S. Maag, C. Quitmann, M. L. Reinle-Schmitt, T. Schmidt, B. Schmitt, A. Streun, I. Vartiainen, M. Vitnis, X. Wang and R. Wullschleger, J. Synchrotron Radiat., 2013, 20, 667-682.

49 P. Hohenberg and W. Kohn, Phys. Rev., 1964, 136, B864.

50 V. Favre-Nicolin and R. Cerny, J. Appl. Crystallogr., 2002, 35, 734-743. 
51 C. Baerlocher and A. Hepp, XRS suite of programs, ETH Zurich, Zurich, Switzerland, 1982.

52 (a) A. D. Becke, J. Chem. Phys., 1993, 98, 5648-5652; (b) M. J. Frisch, G. W. Trucks, H. B. Schlegel, G. E. Scuseria, M. A. Robb, J. R. Cheeseman, G. Scalmani, V. Barone, B. Mennucci, G. A. Petersson, H. Nakatsuji, M. Caricato, X. Li, H. P. Hratchian, A. F. Izmaylov, J. Bloino, G. Zheng, J. L. Sonnenberg, M. Hada, M. Ehara, K. Toyota, R. Fukuda, J. Hasegawa, M. Ishida, T. Nakajima, Y. Honda, O. Kitao, H. Nakai, T. Vreven, J. A. Montgomery, Jr., J. E. Peralta, F. Ogliaro, M. Bearpark, J. J. Heyd, E. Brothers, K. N. Kudin, V. N. Staroverov, T. Keith, R. Kobayashi, J. Normand, K. Raghavachari, A. Rendell, J. C. Burant, S. S. Iyengar, J. Tomasi, M. Cossi, N. Rega, J. M. Millam, M. Klene, J. E. Knox, J. B. Cross, V. Bakken, C. Adamo, J. Jaramillo, R. Gomperts, R. E. Stratmann, O. Yazyev, A. J. Austin, R. Cammi, C. Pomelli, J. W. Ochterski, R. L. Martin, K. Morokuma, V. G. Zakrzewski, G. A. Voth, P. Salvador, J. J. Dannenberg, S. Dapprich, A. D. Daniels, O. Farkas,
J. B. Foresman, J. V. Ortiz, J. Cioslowski and D. J. Fox, Gaussian 09, Revision D.01, Gaussian, Inc., Wallingford CT, 2013.

53 C. Lee, W. Yang and R. G. Parr, Phys. Rev. B: Condens. Matter Mater. Phys., 1998, 37, 785-789.

54 R. Peverati and D. G. Truhlar, Phys. Chem. Chem. Phys., 2012, 14, 16187-16191.

55 (a) J. P. Foster and F. Weinhold, J. Am. Chem. Soc., 1980, 102, 7211-7218; (b) A. E. Reed and F. Weinhold, J. Chem. Phys., 1983, 78, 4066-4073; (c) A. E. Reed, R. B. Weinstock and F. Weinhold, J. Chem. Phys., 1985, 83, 735-746; (d) J. E. Carpenter and F. Weinhold, THEOCHEM, 1988, 46, 41-62; (e) A. E. Reed, L. A. Curtiss and F. Weinhold, Chem. Rev., 1988, 88, 899-926. 56 G. Kresse and J. Hafner, Phys. Rev., 1993, B47, 558-562. 57 P. E. Blochl, Phys. Rev., 1994, B50, 17953-17980.

58 M. Dion, H. Rydberg, E. Schröder, D. C. Langreth and B. I. Lundqvist, Phys. Rev. Lett., 2004, 92, 246401.

59 J. Klimeš, D. R. Bowler and A. Michaelides, Phys. Rev., 2011, B83, 195131. 